\title{
LA LEGITIMACION DEL FRANQUISMO: LOS PLEBISCITOS DE 1947 Y 1966 EN LA PROVINCIA DE ALICANTE
}

\author{
Roque Moreno Fonseret \\ Francisco Sevillano Calero \\ Universidad de Alicante
}

\section{INTRODUCCION}

Desde finales de 1942, se produjo un giro en el proceso de institucionalización de la dictadura franquista como consecuencia de las discrepancias políticas surgidas dentro del régimen por las resistencias al predominio falangista en el "Nuevo Estado" y del viraje que en el desarrollo de la Segunda Guerra Mundial se produjo a favor de los aliados. A partir de entonces, las autoridades franquistas pretendieron "liberalizar" formalmente el sistema político español, abandonando cualquier reminiscencia totalitaria, para aproximarlo a las democracias occidentales a fin de salvaguardar la dictadura adaptándola a las nuevas circunstancias externas. Para ello, se utilizó la imagen política de los católicos y se promovió una serie de reformas políticas y administrativas que instauraban en el país una "democracia orgánica" y, a partir de 1947, una "Monarquía católica, social y representativa". Este largo proceso de institucionalización culminó a finales de los años sesenta, en pleno desarrollismo, con la Ley Orgánica del Estado, una especie de "constitución acabada", y la designación del sucesor de Franco. Dentro de este esquema institucional, la utilización del referéndum por el Estado franquista sirvió principalmente como una forma de legitimación, más allá de la adquirida por la victoria militar en la Guerra Civil, aportando al "Caudillo" y al "Nuevo Estado" un masivo respaldo popular expresado a través de las urnas.

Con la Ley Constitutiva de las Cortes ${ }^{1}$, promulgada el 17 de julio de 1942; se mermaba la hegemonía formal de FET y de las JONS como único canal de participación en la vida política nacional en beneficio de las instituciones extrapartidistas basadas en la representación orgánica de la sociedad española. Después de la derrota de las potencias del Eje en la guerra mundial, el giro institucional del franquismo adquirió un nuevo impulso mediante la promulgación, el 17 de julio de 1945, del Fuero de los Españoles, una especie de "declaración de derechos

\footnotetext{
'Para una aproximación general a las "Leyes Fundamentales" del franquismo, véase: TAMAMES, R.: "La República. La Era de Franco", vol. VII de Historia de España Alfaguara, dir. por M. Artola. Madrid, $1986^{11}$, pp. $439-456$.
} 


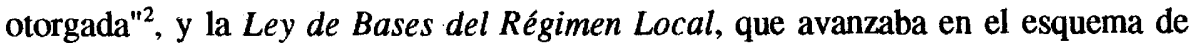
"democracia orgánica" que se pretendía instaurar. Finalmente, se promulgó la Ley de Referéndum Nacional el 22 de octubre del mismo año, con un carácter complementario del sistema electoral orgánico, indirecto y restringido ${ }^{3}$.

En un contexto de condena internacional, de momentáneo renacer de la oposición política en el exilio e interna y de movilizaciones obreras puntuales en 1946 y 1947, las autoridades franquistas culminaron la institucionalización política de la dictadura mediante la promulgación de la Ley de Sucesión a la Jefatura del Estado el 26 de julio de 1947, después de haber sido aprobada en plebiscito el día 6 de julio 4 . La Ley de Sucesión institucionalizaba el régimen salido de la Guerra Civil al proclamar a España como un "Estado católico, social y representativo, que, de acuerdo con su tradición, se declara constituido en Reino" (art. 1) y al establecer un cuerpo legislativo con carácter fundamental (el Fuero de los Españoles, el Fuero del Trabajo, la Ley Constitutiva de las Cortes, la misma Ley de Sucesión y la Ley de Referéndum), -art. 10-. Asimismo, sancionaba la Jefatura del Estado en la persona del General Franco (art. 2) y aseguraba la continuidad del régimen al establecer unos mecanismos de sucesión y al ser el mismo Franco quien había de designar al sucesor. Con el recurso al plebiscito para aprobar el proyecto de la Ley de Sucesión, las autoridades franquistas perseguían la autolegitimación del sistema al reforzar la imagen aperturista del mismo frente a las potencias occidentales en un contexto internacional marcado por el inicio de la "guerra fría" y fortalecer la sensación de apoyo popular al "Caudillo" frente a la oposición política.

La Ley de Principios del Movimiento Nacional, promulgada el 17 de mayo de 1958 por el mismo Franco, sintetizó en un único texto legal las distintas Leyes Fundamentales del Estado franquista hasta entonces vigentes, diluyendo los postulados falangistas dentro del concepto más amplio de "Movimiento Nacional", "entendido como comunión de los españoles en los ideales que dieron vida a la Cruzada". La promulgación de esta ley ha sido explicada como un intento de dar un nuevo impulso al proceso de institucionalización del Estado, mermado por los enfrentamientos dentro del bloque de poder y la crisis económica de estos años ${ }^{5}$.

Durante los años sesenta, la falta de desarrollo político de la dictadura contrastaba

2 BIESCAS, J.A. y TUÑON DE LARA, M.: "España en la dictadura franquista (1939-1975)", en vol. $\mathrm{X}$ de Historia de España, dir. por M. Tunón de Lara. Madrid, Labor, 19902, pág. 213.

${ }^{3}$ Acerca del sistema electoral durante el franquismo, véase: MARTINEZ CUADRADO, M.: "Representación. Elecciones. Referéndum", en La España de los años 70. III, El Estado y la política, t. 1, dir. por M. Fraga Iribarne. Madrid, Ediciones Moneda y Crédito, 1974, pp. 1371-1439; RUIZ DE AZUA, M.A.: "Las elecciones franquistas (1942-1975), en Historia 16, abril de 1977, pp. 85-94; y VANACLOCHA, F.J. y LABOA, J.M".: "El referéndum en España", en Historia 16, $\mathrm{n}^{2} 7$ (noviembre 1976), pp. 24-30.

${ }^{4} \mathrm{El}$ proyecto de la Ley de Sucesión fue presentado por Franco el 31 de marzo. Sobre su tramitación en la Cortes frariquistas, véase: FERNANDEZ, L.M.: "El paso de la Ley de Sucesión por las Cortes Españoles: ¿Hacia la continuidad del régimen?", en Espacio, Tiempo y Forma. Historia Contemporánea, UNED, $n^{\circ} 1$ (1987), pp. 413-438.

5 TAMAMES, R., op. cit., p. 453. 
con el crecimiento económico y la modernización social ocurridos en el país, produciéndose en el país una creciente conflictividad social, que, junto a los postulados políticos del equipo tecnocrático en el Gobierno, llevaron a las autoridades franquistas a practicar una tímida apertura política del sistema para ampliar el consenso con el mismo ${ }^{6}$. Con este objeto, la Ley Orgánica del Estado, aprobada en plebiscito el 14 de diciembre de 1966 y promulgada el 10 de enero de 1967 , pretendía dar formalmente la coherencia de una Constitución democrática al conjunto de las Leyes Fundamentales, depurar su vocabulario cargado de reminiscencias fascistas e introducir algunas reformas políticas. Finalmente, la institucionalización de la dictadura culminó el 22 de julio de 1969 con la designación del príncipe Juan Carlos como sucesor del Jefe del Estado con la dignidad de Rey, asegurando para el futuro la continuidad del régimen.

\section{LOS PROCEDIMIENTOS PARA LA APLICACION DEL REFERENDUM Y LA MANIPULACION ELECTORAL}

La adopción de la institución del referéndum en el régimen franquista obedeció al deseo de enfatizar la pretendida apertura política del sistema político español buscando su acercamiento a las democracias occidentales, que en la postguerra mundial estaban incorporando esta forma de democracia semidirecta en sus nuevas constituciones. Así, la Ley de Referéndum de 22 de octubre de 1945 establecía:

"Abierta para todos los españoles su colaboración en las tareas del Estado a traves de los organismos naturales, constituidos por la familia, el municipio y el sindicato (...), esta Jefatura del Estado (...) ha creído conveniente instituir la consulta directa a la Nación en referéndum público en todos aquellos casos en que, por la trascendencia de las leyes o incertidumbres en la opinión, el Jefe del Estado estime la oportunidad y conveniencia de esta consulta.

En su virtud, dispongo:

Artículo $1^{\circ}$ Cuando la trascendencia de determinadas Leyes lo aconseje o el interés público lo demande, podrá el Jefe del Estado, para mejor servicio de la Nación, someter a referéndum los proyectos de Leyes elaborados por las Cortes.

Artículo $2^{\circ}$ El referéndum se llevará a cabo entre todos los hombres y mujeres de la Nación mayores de veintiún años (...)"?

Por consiguiente, y como se indicaba en el Preámbulo, el recurso al referéndum

\footnotetext{
${ }^{6}$ Para la modemización de la sociedad española y la labor política e ideológica de los tecnocratas del Opus Dei en el Gobiemo para salvar la contradicción con la falta de desarrollo político del Estado franquista, véase: ORTI BENLLOCH, A.: "Política y sociedad en el umbral de los años setenta: las bases sociales de la modemización política", en Cambio social y modernización política. Anuario político español 1969, dir. por M. Martínez Cuadrado. Madrid, EDICUSA, 1970, pp. 5-90.

${ }^{7}$ Boletín Oficial del Estado (B.O.E.), 24-X-1945.
} 
tenía un carácter complementario del sistema electoral orgánico. Asimismo, se trataba de un tipo de referéndum "potestatario", siendo su convocatoria facultad exclusiva de Franco (la obligatoriedad del referéndum para modificar o derogar las Leyes Fundamentales se estableció en el art. 10 de la Ley de Sucesión), y "previo", afectando tan sólo a los proyectos de ley (el art. 65 de la L.O.E. incluyó también las proposiones de ley). Finalmente, se incluía el único caso de sufragio universal reconocido en el sistema electoral franquista. Estos rasgos, junto a la naturaleza dictatorial del sistema político español, explican el carácter plebiscitario de esta ley, con una ingerencia del Estado en la sociedad para forzar la adhesión al "Caudillo" y al "Nuevo Estado".

Con motivo de la celebración de los plebiscitos, se promulgaron una serie de normas complementarias. Aparte de las disposiciones tendentes a la formación del censo de los mayores de veintiún años, el decreto de 8 de mayo de 1947 fijaba las normas de aplicación del plebiscito de $1947^{8}$, en las que bajo una aparente legalidad en los procedimientos se hallaba recogida una serie de disposiones claramente distorsionadoras de los resultados:

-La obligatoriedad del voto, con la imposición de sanciones económicas a quienes se abstuvieran de hacerlo, y la exclusión de aquellas personas condenadas judicialmente, descartando de este modo al enorme número de represaliados políticos (art. $3)$.

-El control de las mesas electorales, sobre todo de los presidentes y los adjuntos, que eran propuestos, siguiendo el esquema orgánico, por los alcaldes, las delegaciones sindicales y las asociaciones profesionales locales (art. 8).

-La obligatoriedad de demostrar la identidad personal por parte de los electores sólo a petición explícita de los miembros de la mesa (art. 21).

-La falta de garantías en el escrutinio al no tener el presidente la obligación de manifestar cada papeleta al resto de los miembros de la mesa y, una vez concluido el recuento, no contrastarse el número de votos emitidos con el de los votantes anotados (art. 23).

-La falta de garantías en la estimación de los recursos por la brevedad del plazo de impugnación, un solo día después de la votación, y la ausencia del derecho de presentación en las instancias superiores durante la tramitación del recurso (arts. 2933).

Por su parte, la orden de 20 de junio de $1947^{9}$ introducía algunas normas complementarias muy importantes, como la obligación de acreditar el haber ejercido el voto en el referéndum (art. 1), la regulación del voto de los llamados "transeúntes", destinados a convertirse en importantes correctores de votos en aquellas localidades donde fuera necesario (art. 2), y la concesión de voto a los miembros del Ejército, claramente identificados con el régimen (art.3).

Pero además de las posibilidades coercitivas ofrecidas por la legislación para la aplicación del referéndum, y aprovechando las mismas, se arbitró una serie de

\footnotetext{
${ }^{8}$ B.O.E., 9-V-1947.

${ }^{9}$ B.O.E., 25-VI-1947.
} 
medidas ilegales de manipulación directa de los votos que debían ser aplicadas por los presidentes de las mesas ${ }^{10}$.

A raíz de la convocatoria del referéndum de 1966, el decreto de 21 de noviembre de 1966 , completado con la orden de 29 del mismo mes ${ }^{11}$, simplemente actualizaba la legislación complementaria de mayo de 1947, con la única innovación de que serían los alcaldes de los municipios los únicos que propondrían los miembros de las mesas electorales.

\section{PROPAGANDA OFICIAL DURANTE LOS PLEBISCITOS}

La coacción política hasta ahora descrita estuvo acompañada de la presión ideologica ejercida por el Estado a través de los medios de comunicación social. Ante la convocatoria del referéndum para aprobar el anteproyecto de la Ley de Sucesión, desde la Delegación General de Prensa se dictaron las consignas a cumplir por todos los diarios y revistas del país ${ }^{12}$, ordenando que la campaña periodística se habría de ajustar a los siguientes puntos:

-El estudio de la Ley de Sucesión, señalándose que en el mismo se debería insistir en que la ley obedecía a la necesidad de institucionalizar el nuevo régimen bajo la forma de un "Reino católico, social y representativo", enlazando con la tradición española, por imperativos de índole interna y no por presiones externas; esta ley, se decía, estaba inspirada directamente por Franco y no significaba ni la revisión de los principios del Movimiento ni la "instauración" inmediata de la monarquía, lo que quedaba al arbitrio del Jefe del Estado.

-El estudio de la Ley de Referéndum y el decreto complementario de 8 de mayo de 1947, habiéndose de indicar la obligatoriedad del voto y que era "obligación ineludible de todo buen español votar a favor de dicha Ley".

-El estudio de las Leyes Fundamentales recogidas en la Ley de Sucesión y de los principios más significativos del Movimiento.

-La constatación de la obra concreta del régimen "en el orden social, cultural, sanitario y religioso".

En líneas generales, la campaña propagandística desarrollada por la prensa alicantina desde principios de junio, principalmente el diario Información, perteneciente al Movimiento, se ajustó estrictamente a las consignas señaladas. En los primeros días, los editoriales del mencionado diario insistieron en la necesidad y el carácter de la Ley de Sucesión según los términos ya indicados, para en los días

\footnotetext{
${ }^{10}$ Archivo General de la Administración (A.G.A.), Sección Gobemación (S.G.), c. 3519, Instrucciones confidenciales para los presidentes. Véase, asimismo, MIRANDA ENCARNACION, J.A. y PEREZ ORTIZ, J.F.: "El franquismo intranquilo: la manipulación electoral en el referéndum de 1947", en Estudios sobre la derecha española contemporánea, dir. por J. Tusell, J. Gil Pecharromán y F. Montero. Madrid, UNED, 1993, pp. 597-612.

${ }^{11}$ B.O.E., 22-XI-1966 y 30-XI-1966 respectivamente.

${ }^{12}$ A.G.A., S.G., c. 3519, circular reservada, 18-VI-1947.
} 
anteriores al plebiscito reiterar la obligación de todo español de votar afirmativamente, en último término, por la defensa del "orden" y la "religión" frente a la amenaza del "comunismo". En un editorial de este mismo diario, se escribía unos días antes de la consulta:

"Lo que votas diciendo 'SI'. Que España se constituye en Reino católico, social y representativo. Que Franco continúa siendo Jefe del Estado. Que España garantiza su libertad e independencia con instituciones de tipo permanente para el futuro. Que no se perderá en el porvenir el espíritu cristiano de reformas sociales que inspira el Movimiento. Que el pueblo español decide por si mismo, sin ingerencias ni extrañas intromisiones, la forma de gobierno que estima más conveniente. Que la Monarquía que se instaure estará al servicio de la Nación. Que el comunismo se estrellará siempre contra la inexpugnable fortaleza de la unidad del pueblo español. Que el propio Caudillo Franco irá convirtiendo en realidad las normas de la Ley de Sucesión en el momento que estime oportuno. Así pués, el deber de todo buen español es votar 'SI'. Lo quiere Franco. Lo exige España" ${ }^{113}$.

Por su parte, las hojas propagandísticas impresas con motivo del plebiscito, por su misma sencillez de ideas y fácil accesibilidad, contenían mayoritariamente mensajes más cercanos a los intereses inmediatos de los distintos colectivos sociales, resaltando la labor concreta del régimen hasta entonces desarrollada o por realizar ${ }^{14}$. En general, puede señalarse que la consulta de 1947 tuvo fundamentalmente un carácter plebiscitario de la persona de Franco y el nuevo régimen por el representado.

Por su parte, la campaña propagandística desarrollada con motivo de la celebración del plebiscito de 1966, con una nueva administración comunicativa en la que había desaparecido la censura previa, no giro en torno a la figura de Franco, ni siquiera a la propia L.O.E., sino que se insistió, en medio de la efervescencia desarrollista que sacudía al país, en los valores perennes supuestamente representados por el régimen y la necesidad de su ratificación de cara a la estabilidad futura del país $^{15}$. Además de señalarse la jefatura vitalicia de Franco, la continuidad y culminación del proceso institucionalizador del régimen, y el carácter pretendidamen-

13 "Lo que votas diciendo 'SI", Información, 2-VII-1947, p. 1.

${ }^{14}$ Archivo Municipal de Denia (A.M.D.), c. 467. Algunos ejemplos significativos del contenido de estas hojas son:

" Trabajador! FRANCO ha establecido SEGUROS para todas las ENFERMEDADES"

"iIndustrial! La industria de España NECESITA SER POTENTE. Precisa tranquilidad para poder servir a España y al extranjjero sus artículos. Para ello, nuestro deber es votar con un SI el Referéndum"

${ }{ }_{i}$ Hombre de comercio! Diez y ocho puertos españoles han sido ampliados, llevándose a cabo en ellos obras que los colocan junto a los primeros de Europa. El votar que SI en el Referéndum es obligación de español"

"iCatólico!! FRANCO ha construído en sus últimos años de Gobiemo OCHO SEMINARIOS"

${ }^{15}$ Las diferencias de carácter entre los plebiscitos de 1947 y 1966 ya fueron puestas de manifiesto por MARTINEZ CUADRADO, M., op. cit., pp. 1431-1435. 
te "democrático" de la nueva ley, en un editorial del diario alicantino Información se afirmaba días antes del plebiscito:

"El largo y fecundo ciclo de la paz española. Las gentes españolas, de todas las edades y todas las clases, han comprendido perfectamente que esta nueva etapa nacional, la que abre la Ley Orgánica del Estado, es la etapa de la consolidación de una gran obra y, como consecuencia de ello, la apertura hacia un porvenir en el cual los valores eternos, comunes a todas las generaciones, sean expresados con las formas nuevas que los nuevos tiempos exigen"16.

Siendo los "valores eternos" representados por el régimen franquista:

"PATRIA, PROGRESO, JUSTICIA, PAN, BIENESTAR, SEGURIDAD, PORVENIR, DESARROLLO, PAZ, CONCEDELES TU 'SI' EN EL REFERENDUM NACIONAL DE $1966^{\prime 17}$.

\section{EN TORNO A LA FIABILIDAD Y EL SIGNIFICADO DE LOS RESULTADOS ELECTORALES}

El estudio de los resultados de consultas electorales realizadas en países no democráticos no permite descubrir las posturas ideológicas o la magnitud de las tensiones políticas que existen entre las diferentes clases sociales o distintos ámbitos espaciales como lo hacen las investigaciones electorales centradas en regímenes democrático-liberales. No obstante, un análisis exhaustivo de dichos resultados puede facilitarnos algunos datos sobre las diferentes actitudes políticas o la distribución de las corrientes de opinión que otro tipo de fuentes no nos pueden proporcionar. En cualquier caso, dicho análisis debe tener siempre presente, por un lado, el contexto en el que los plebiscitos se han realizado (ausencia de libertad, desconocimiento del tema sometido a consulta e inexistencia de competición entre fuerzas políticas en igualdad de condiciones), y por otro, el grado de garantía que ofrezcan los resultados hechos públicos.

A la hora de analizar los plebiscitos realizados durante el franquismo hay que tener en cuenta, pues, los factores mencionados que, en grado superlativo, condicionaron el desarrollo de las elecciones y el escrutinio final. Como hemos visto, la propaganda unilateral y obsesiva, el clima de amenaza y coacción, la ignorancia de lo que se votaba, el temor a una nueva guerra civil o las facilidades de todo tipo dadas para el voto afirmativo mediatizaron al elector; los resortes empleados por la administración franquista, la composición de las mesas o el voto "transeúnte" manipularon los datos en mayor o menor medida y, en consecuencia, confirieron una

\footnotetext{
16 "El largo y fecundo ciclo de la paz española", Información, 11-XII-1966, p. 5.

${ }^{17}$ Información, 2-XII-1966, p. 8, reproducción de las papeletas enviadas a cada elector junto al sobre de votación.
} 
dudosa fiabilidad a las cifras manejadas.

Pero es opinión unánimemente compartida por todos los investigadores que se han centrado en el análisis de los plebiscitos de 1947 y 1966 que los resultados son, cuando menos, significativos. Los datos, ciertamente falseados, reflejan globalmente el estado de opinión existente en aquellos momentos en España y, recordemos, en ambas elecciones la participación rond6 el $90 \%$ y el voto afirmativo fue algo superior a ese porcentaje. Justifican dicha afirmación con argumentos tan variados como la presencia de una amplia masa derechista en España ${ }^{18}$ o la persistencia de causas subyacentes en el comportamiento electoral de algunas circunscripciones ${ }^{19}$. Son variables que, indudablemente, existieron y explican en parte los resultados. Pero, por encima de ellas, el escrutinio final no refleja sino la capacidad de la administración franquista para movilizar y coaccionar a la población.

Por ello resulta difícil y, en ocasiones hasta imposible, explicar los resultados habidos en las diferentes circunscripciones electorales recurriendo a las variables sociológicas clásicas, como la población, nivel de renta o industrialización, la tradición política o electoral, etc ${ }^{20}$. La misma homogeneidad en los resultados habla en este sentido: en 1947, por ejemplo, aunque existió una variación relativamente importante de participación, de 20,13 puntos, los que van desde el mínimo (Oviedo, $76,85 \%$ ) al máximo (Valladolid, 96,98\%), en la gran mayoría de provincias votó entre el 80 y el $90 \%$ del censo electoral. Sí parece que hubo, no obstante, una correlación entre la variable socioeconómica y la participación que explicaría, en su caso, la "alta" abstención relativa de las provincias de Madrid, Barcelona, Vizcaya o Sevilla en los dos plebiscitos.

\section{LOS RESULTADOS DE LOS PLEBISCITOS DE 1947 Y 1966 EN LA PROVINCIA DE ALICANTE}

En la provincia de Alicante, los resultados oficiales de los plebiscitos analizados

${ }^{18}$ TOMAS VILlaRROYA, J.: "El Referéndum de 1947" en Política y Sociedad. Estudios en homenaje a Francisco Murillo Ferrol. Madrid, Centro de Investigaciones Sociológicas, 1987, vol. II, pp. 683.

${ }^{19}$ LÓPEZ GUERRA, L.: "Abstencionismo electoral en contextos no democráticos y de transición: el caso español", en Revista Española de Investigaciones Sociológicas, $\mathrm{n}^{\circledR} 2$ (abril-junio de 1978), pp. 53-69.

${ }^{20}$ Todos los autores que han analizado los resultados de los plebiscitos franquistas en diferentes circunscripciónes insisten en la dificultad de explicar los datos atendiendo a comportamientos electorales pasados o a factores sociales y/o económicos. Véanse, en este sentido, los trabajos de IZQUIERDO COLLADO, J. de D.: "El Referendum de 1947. Antecedente del Referendum de la Ley de Reforma Política de 1976", en Al-Basit, no 14 (mayo 1984), pp. 179-202 (para el caso de Albacete); ÁNGUERA, P.: "Participació i refús a dos referendums franquistes a l'Alt Camp: 1947 i 1966", en Quaderns de Vilaniu, no 4, 1983, pp. 15-21; y EQUIPO DE SOCIOLOGÍA ELECTORAL: "Las elecciones franquistas en Barcelona", en Historia 16, abril de 1977, pp. 129-136. 
son también homogéneos ${ }^{21}$. La participación electoral fue, en ambos casos, muy elevada, situándose en la mayoría de las poblaciones por encima del 90\%. Esta baja abstención, inferior a la media nacional, se explica en parte por el tradicional comportamiento del electorado alicantino, que durante la Segunda República había mostrado una fuerte y creciente participación que hizo, por ejemplo, que la abstención "de tipo político" de noviembre de 1933 fuese comparativamente baja ${ }^{22}$.

No constatamos una continuidad en los niveles de participación/abstención entre ambas consultas. Aunque la participación fue casi la misma $(92,35 \%$ en 1947 y $92,31 \%$ en 1966), en la primera encontramos mayores diferencias entre poblaciones. La abstención fue algo mayor en los municipios industriales e historicamente decantados hacia candidaturas progresistas de la Hoya de Castalla y del Valle del Vinalop $\sigma^{23}$. Debemos entender este abstencionismo como "activo", en tanto en cuanto no se debe a una falta de sensibilización política sino, por el contrario, a una posición política determinada, la de rechazo consciente del sistema político. Sin embargo, fue más baja que la media en la capital y en Alcoy y su comarca, zona ésta última donde el anarquismo tuvo una fuerte implantación y sus consignas abstencionistas fueron seguidas disciplinadamente ${ }^{24}$.

El rechazo al Régimen de Franco, en estos últimos casos, se concretó en el alto porcentaje de votos negativos $(15,15 \%$ en Alcoy y $7,09 \%$ en la capital). La variable socioeconómica explica la presencia reseñable de votos contrarios, pues éste predomina en las localidades más populosas y con mayor desarrollo (además de las vistas, Agost, 8,44; San Vicente, 7,06; Novelda, 5,70; Elda, 5,59; Santa Pola, 5,34; Ibi, 4,64; Petrel, 4,47; Elche, 4,19). El voto afirmativo, por el contrario, predominó en las poblaciones agrarias de la Marina Alta y Baja, Alto Vinalopó y, sobre todo, Bajo Segura. En esta última comarca, el porcentaje de votos favorables sobrepasó holgadamente el $99 \%$, en consonancia, por otra parte, con su tradicional inclinación a posturas políticas conservadoras.

En definitiva, el rechazo global (aquel que suma la abstención, votos negativos

\footnotetext{
${ }^{21}$ La dispersión intercomarcal osciló entre el $86,89 \%$ del Bajo Vinalopó y el $94,74 \%$ de la Marina Baja para 1947, y el 90,38\% del Bajo Segura y el 93,82\% del Bajo Vinalopó para 1966.

${ }^{22}$ A pesar de que fue un factor determinante en los resultados electorales, en las elecciones de 1933 la abstención $(32,17 \%)$ ascendió sólo ligeramente en comparación a la celebrada dos años antes $(30,48 \%)$. Salvo en los distritos netamente obreros de las localidades más industrializadas de la provincia de Alicante (sobre todo Elda y Villajoyosa), la consigna abstencionista defendida por la CNT no fue seguida mayoritariamente. Además, buena parte de la masa abstencionista se debió a la no participación de la mujer que, por primera vez en España, pudo ejercer su derecho al voto. Véase GARCIA ANDREU, M.; MORENO FONSERET, R. y SANTACREU SOLER, J.M.: "El anarcosindicalismo alicantino durante la Segunda República", en El anarquismo en Alicante 1868-1945. Alicante, Instituto de Estudios Juan Gil Albert, 1986, pp. 47-56.

${ }^{23}$ El comportamiento electoral de la provincia de Alicante durante la Segunda República puede verse en FORNER MUÑOZ, S.: Industrialización y movimiento obrero. Alicante 1923-1936. Valencia, Institució Alfons el Magnànim, 1982. pp. 319-375.

${ }^{24}$ En la ciudad de Alcoy la política electoral cenetista tuvo especial importancia entre los obreros textiles y metalúrgicos y se materializó repetidamente en el distrito III. Véase GARCIA ANDREU, M.; MORENO FONSERET, R. y SANTACREU SOLER, J.M., op. cit., p. 51.
} 
y nulos ${ }^{25}$ ) fue mucho mayor en aquellos municipios con unas características socioeconómicas específicas: economía basada en la industria o el servicio, con una alta proporción de población obrera y que tradicionalmente se habían mostrado proclives a posturas de izquierdas. Los resultados electorales habidos en la ciudad de Alicante refrendan esta última afirmación. Los distritos marcadamente obreros (I, V, VI y VIII) demostraron un mayor grado de disconformidad a través del voto negativo, que superó siempre el $8 \%$ del total. En los distritos con nivel de renta mayor, aquellos donde estaban instalados el alto comercio y las profesiones más cualificadas (II y III), el voto afirmativo superó con mucho la media de la ciudad. Es reseñable, en cualquier caso, el bajo nivel de participación del distrito II, explicado por la composición demográfica de sus habitantes, entre los que predominaba la población anciana (el 10\% era mayor de 60 años) y femenina (casi el $60 \%$ ), más refractarias tradicionalmente a la participación política. Entre los distritos obreros y acomodados se encuentran aquellos de clase media o media-baja, donde el porcentaje de voto negativo alcanzo significativamente niveles intermedios. En el distrito IV, donde las clases medias estában repartidas homogeneamente y existió desde siempre una fuerte influencia eclesiástica, el voto negativo sobrepasó el 5\%; en el distrito VII, donde la disparidad era mayor y existían barrios de alto comercio (Mercado), de clase media y alta (Salesianos) y obrero (zona norte de Pérez Galdós), el voto desfavorable se situó en el 7,85\%. La distribución de la participación y del voto afirmativo refleja la persistencia de valores subyacentes: en los distritos donde el apoyo al Frente Popular fue mayor en las elecciones de 1936 existió un rechazo señalado en la consulta de 1947; por el contrario, los distritos en los que la candidatura antimarxista obtuvo un mayor porcentaje de votos mostraron una fervorosa adhesión al Régimen. También en estos últimos distritos la participación, tradicionalmente más baja, se situó por debajo de la media de la ciudad ${ }^{26}$.

En el Referendum de 1966 desaparecieron muchas de estas diferencias. Si obviamos, como único aspecto reseñable por su continuismo, el "alto" porcentaje de votos negativos existente en Alcoy $(4,04 \%)$, los resultados son extraordinariamente homogéneos. Como hemos visto, las diferencias de carácter entre un referendum y otro, la abulia de los españoles hacia este tipo de consulta en un clima de desarrollo económico y, como no, la presión ambiental y el empleo de todos los resortes administrativos comentados, jugaron a favor del Régimen en un porcentaje elevado. Pero quizás mayor influencia tuvo el voto "transeúnte" en estas elecciones, en las que más de dos millones de personas pudieron votar en toda España con sólo presentar su carnet de identidad en municipios distintos a los de su residencia habitual. No

\footnotetext{
${ }^{25}$ En la mayoría de las ocasiones, el voto nulo tuvo una carga de rechazo mayor que el mismo voto negativo, puesto que eran anulados debido a sus inscripciones ofensivas contra el Régimen y, sobre todo, contra el general Franco. Como quiera que los votos anulados debían conservarse, hemos encontrado muchos de ellos en diferentes archivos municipales. Véanse, por ejemplo, la fuerte dosis de rechazo y odio que se observa en algunos de los votos existentes en el A.M.D., c. 467.

${ }^{26}$ Un espléndido análisis de las elecciones de 1936 en la ciudad de Alicante y, en general, de las cuatro elecciones republicanas, puede verse en García Andreu, M., Alicante en las elecciones republicanas 1931-1936, Universidad de Alicante, 1985.
} 
cabe duda que este hecho actuó como corrector del voto en numerosas localidades ${ }^{27}$, sobre todo en las más pobladas: Alicante y su comarca y las localidades marítimas, donde no parece que en ese año y en pleno mes de diciembre la población de paso alcanzase porcentajes cercanos a la cuarta parte del volumen demográfico total.

\section{CONCLUSIONES}

Los plebiscitos de 1947 y 1966, aunque con diferencias de carácter reseñables, fueron concebidos como instrumentos de legitimación del régimen. En ambos, la administración franquista se volcó para conseguir unos resultados que respaldaran "legalmente" a la dictadura y a su máximo mandatario frente a la oposición y a las democracias occidentales.

La gran participación y el alto porcentaje de votos afirmativos que reflejaron los datos oficiales demostraron que el sistema tenía una gran capacidad para llevar a cabo una movilización de la población, coactiva pero efectiva, y que, además, podía manipular a los electores y a los votos a través de una amplia gama de mecanismos amparados por la ley o al margen de ella. En una provincia como la de Alicante, con un comportamiento electoral decantado hacia la izquierda y donde los cambios socioeconómicos ocurridos durante la guerra civil habían calado más que en cualquier otro lugar de España, la participación superior al $92 \%$, con un voto afirmativo del $95 \%$ en ambos casos, demuestra hasta que punto el régimen alcanzó sus propósitos.

Ahora bien, no hay que perder de vista nunca que esos resultados no fueron los reales; los datos fueron manipulados antes, durante y después de la celebración de los plebiscitos. El hecho de que en los primeros escrutinios haya un mayor número de votantes que de electores, de que en numerosas localidades (lógicamente las más pequeñas)llegase a votar afirmativamente el $100 \%$ de la población, la misma homogeneidad de los resultados o el alto número de transeúntes en el referendum de 1966 nos inclina a pensar que las correcciones fueron muchas.

No obstante, los datos pueden ser indicativos respecto a la persistencia de determinadas variables sociológicas. En los municipios y comarcas con un pasado electoral republicano e izquierdista, con una economía más industrializada o terciarizada y con un importante volumen de población obrera, el rechazo global fue mayor, bien expresado a través de la abstención, bien mediante el voto negativo. Por ello, este rechazo es mayor en las comarcas de L'Alcoiá y el Campo de Alicante. Por el contrario, en los municipios agrarios, de claro pasado conservador, el voto fue mayoritariamente positivo. En cualquier caso, tampoco conviene magnificar estas correlaciones, pues, en los dos consultas, los datos favorables al régimen fueron

\footnotetext{
${ }^{27}$ Archivo Municipal de Villena (A.M.V.), c. 908. El 20 de enero de 1967, el Gobemador Civil de Alicante envió una circular a todos los ayuntamientos de la provincia ordenando que se hicieran las correcciones oportunas de sus respectivos censos electorales de 1965, dadas las anomalías observadas con ocasión del pasado referéndum de diciembre de 1966 y que habían dado lugar a todo tipo de rumores.
} 
superiores a la media nacional.

Por ello, cabría concluir que el régimen consiguió formalmente su propósito de legitimación de la dictadura. 


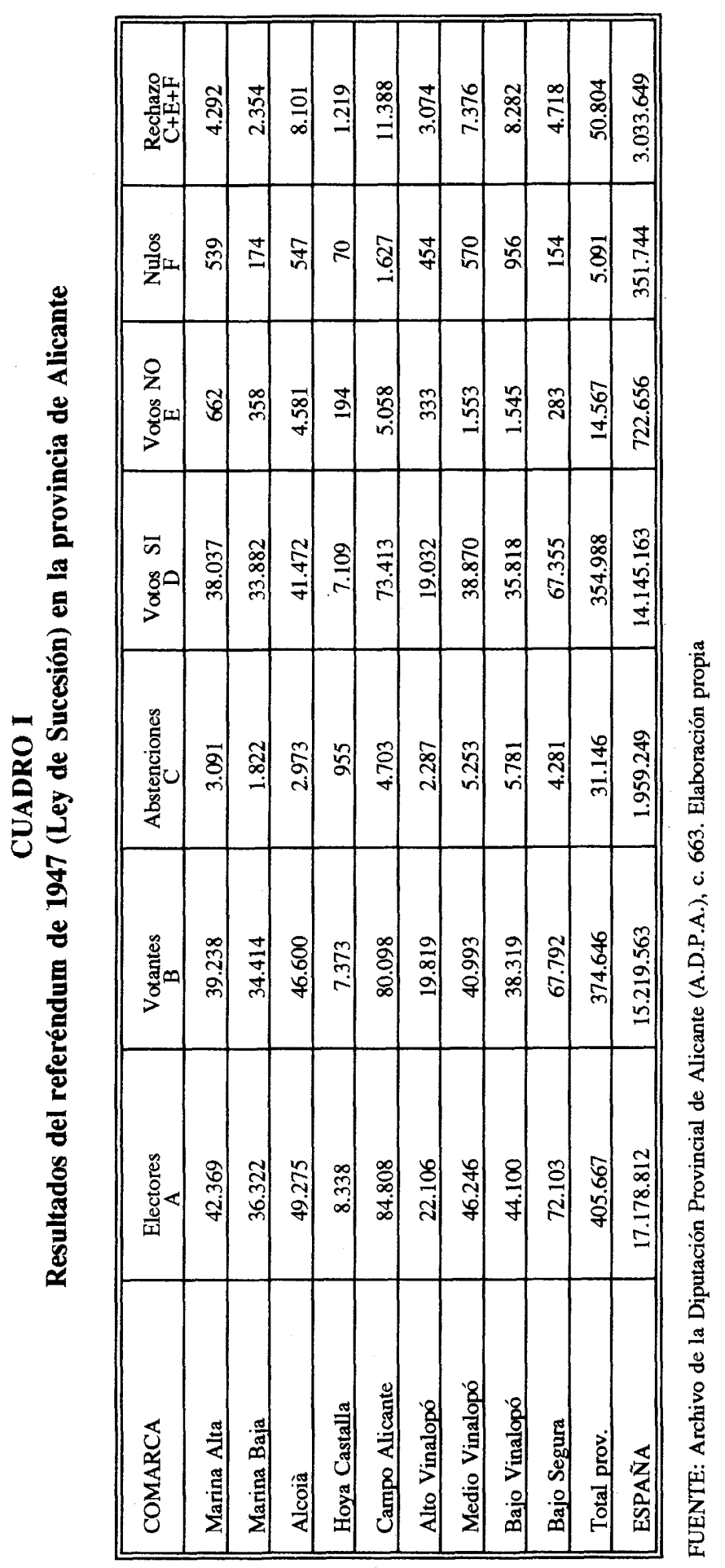




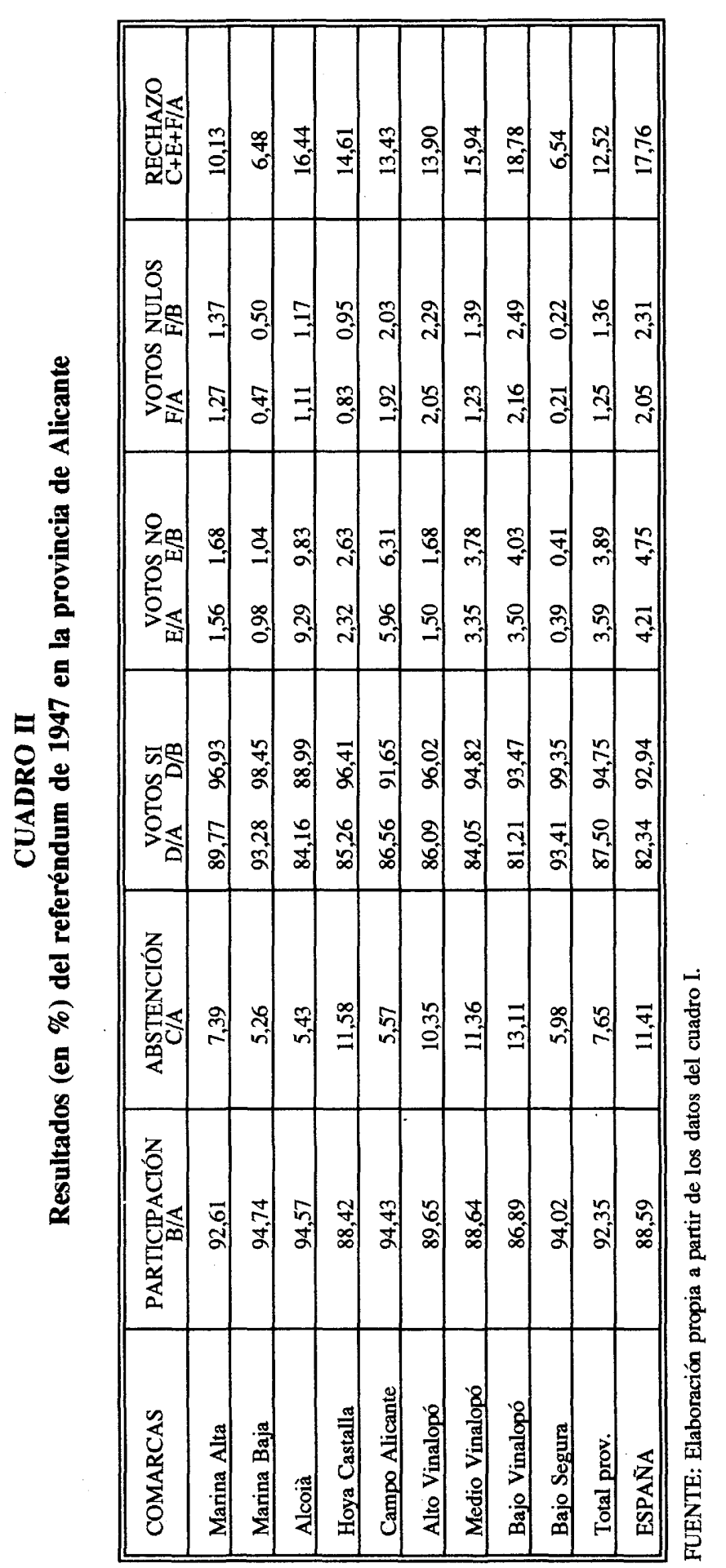




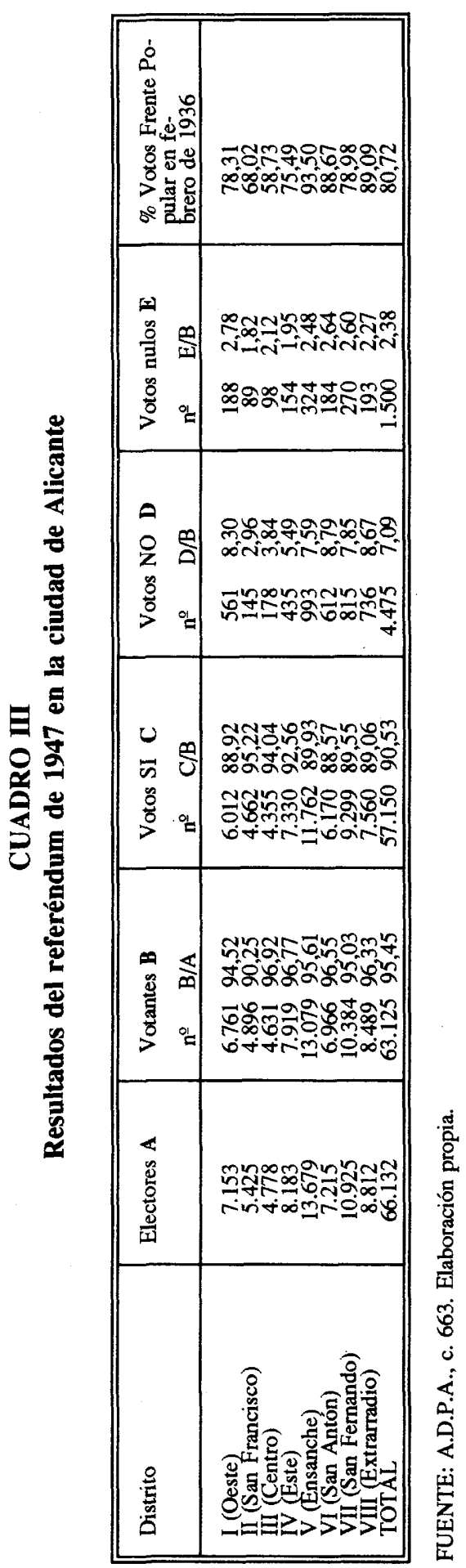




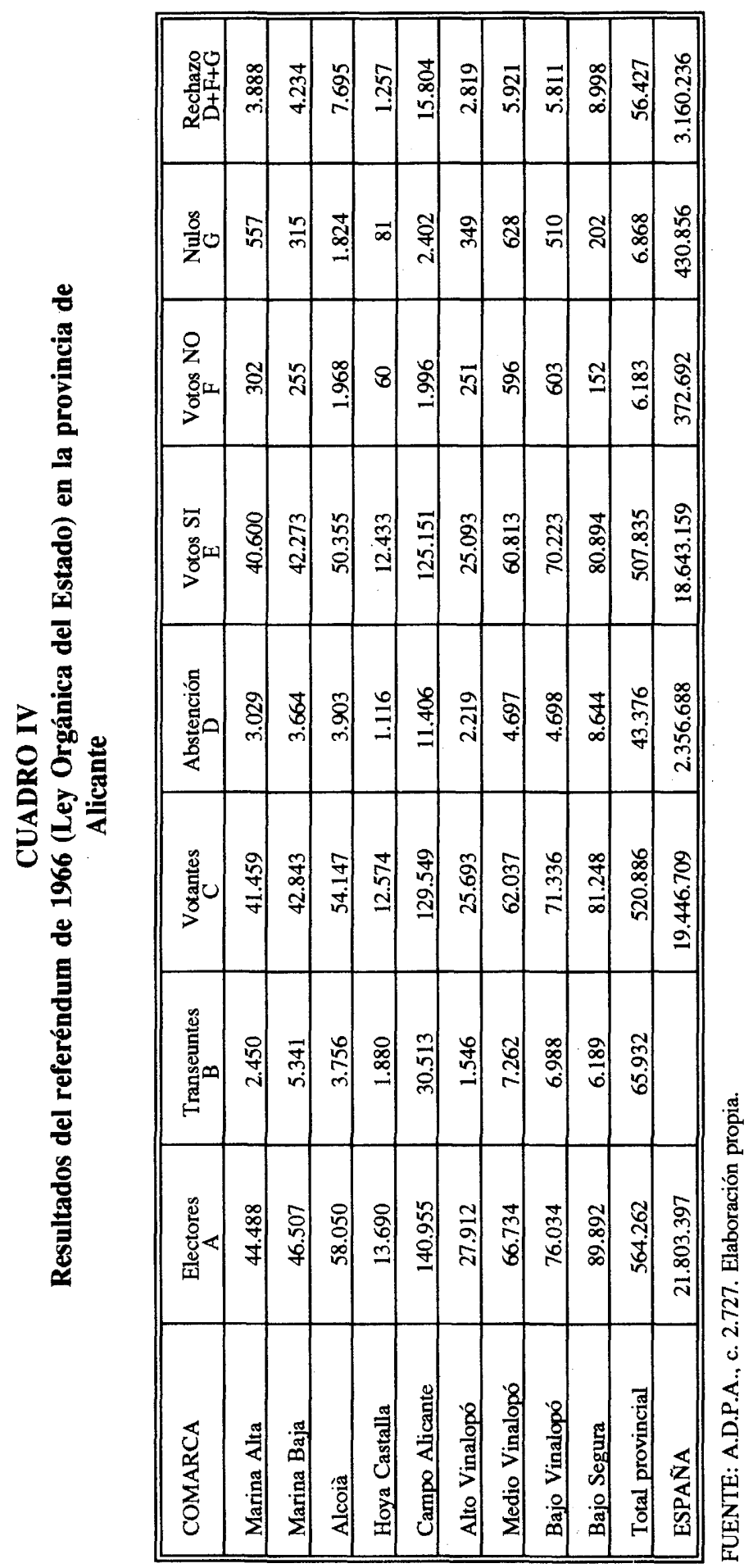




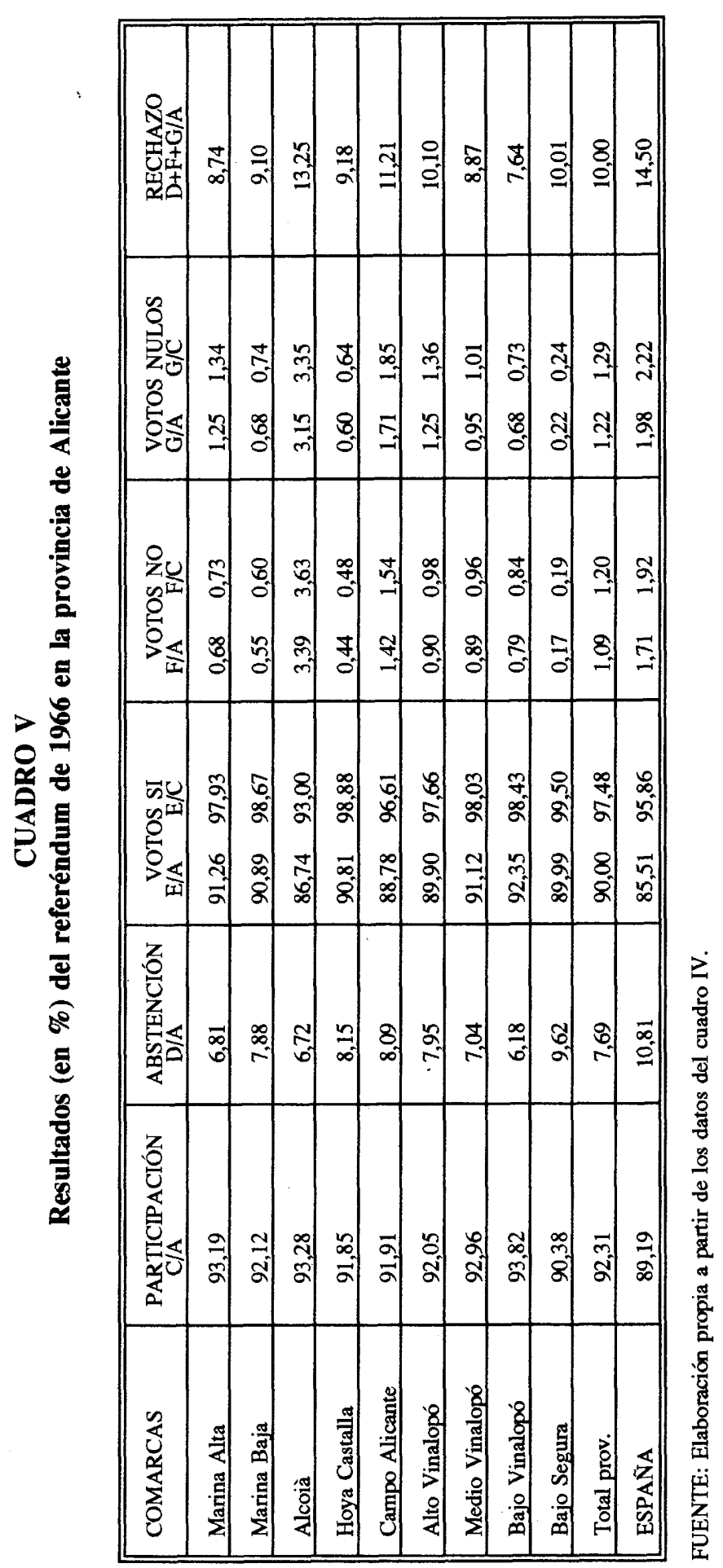




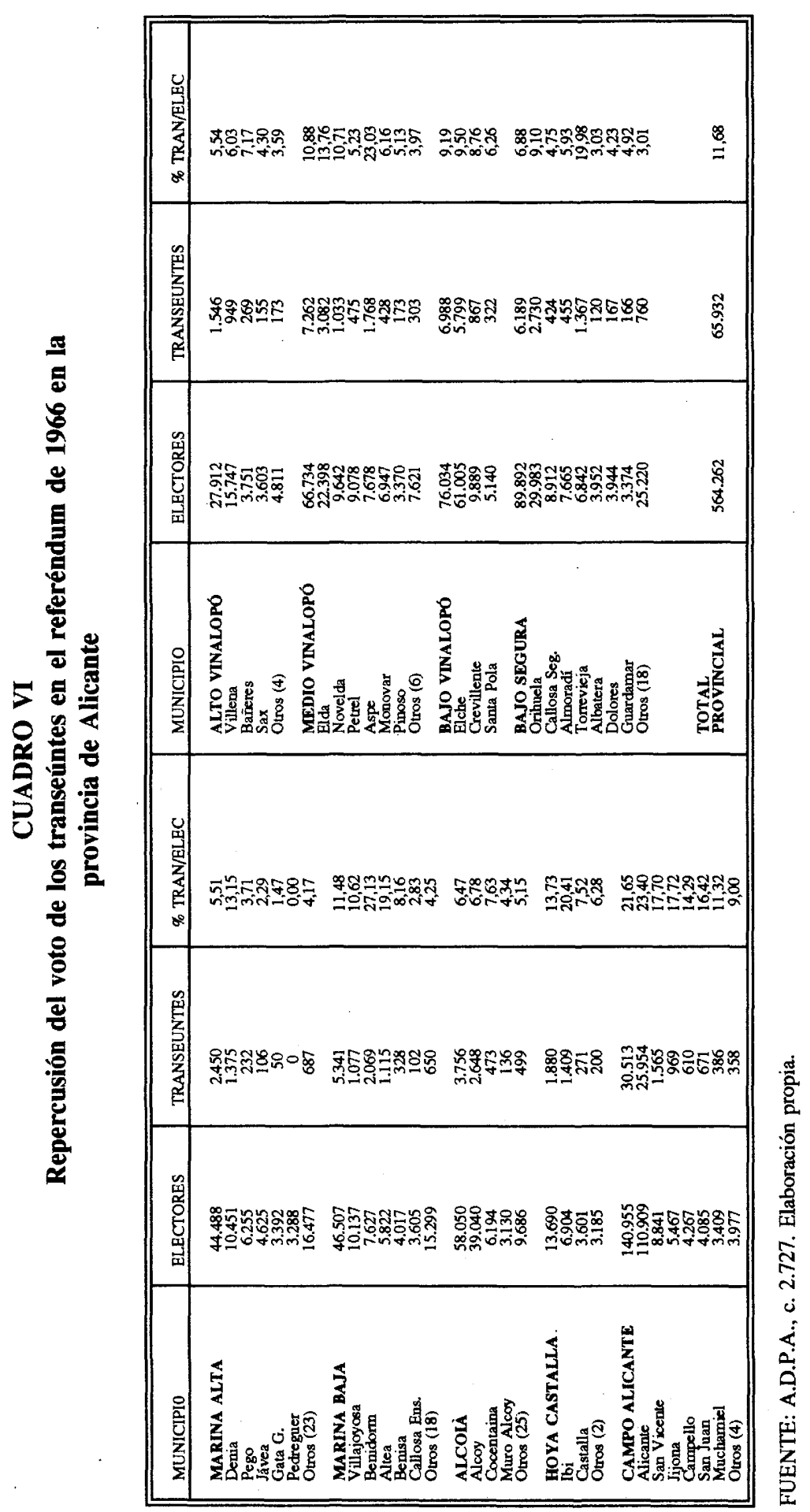

